\title{
Apresentação do Dossiê
}

\section{"Elementos para políticas brasileiras de acervos digitais em memória e cultura"}


Discutir políticas públicas no Brasil em tempos de predomínio das ideologias de estado mínimo e privatizações se torna um desafio. No entanto, é esse tipo de desafio que tem que ser enfrentado pela Universidade e por um periódico acadêmico como PragMATIZES. Estamos numa época em que qualquer um que dispõe de audiência nos meios de comunicação se arvora com autoridade para falar superficialidades (que nada mais são do que suas próprias opiniões desinformadas). Ao contrário do que sugerem as mentalidades tacanhas e superficiais, cada vez é mais necessário discutirmos e refletirmos sobre as questões da Cultura em nosso país. O presente Dossiê é uma oportunidade para isso, em um tema ainda pouco discutido, inclusive pela academia, o das políticas públicas para acervos digitais em Memória e Cultura.

Embora o Brasil tenha uma longa trajetória de estado intervencionista e de planejamento econômico e social, o setor de Cultura tem sido pouco contemplado. Se comparado, por exemplo, ao setor de pesquisa em Ciência \& Tecnologia e pós-graduação, o Brasil tem uma larga experiência de planejamento e implantação de, não somente políticas de governo, mas sim políticas de estado, que perduram ao longo de décadas e de governos. Os governos militares, desde a década de 1970, implantaram os PBDCTs - Planos Básicos de Desenvolvimento Científico e Tecnológico - o I, de 1973 a 1974, o II, de 1975-1977, e o III, de 1980 a 1985. Essas políticas tiveram continuidade com a redemocratização, foram ratificadas e mesmo ampliadas com a Constituição de 1988, que ampliou as fontes de financiamento, destinando percentagens do orçamento nacional para o desenvolvimento científico e tecnológico. A Constituição de 1988 também influenciou fortemente as legislações estaduais, que criaram as fundações de amparo à pesquisa por estado e também destinaram percentagens dos orçamentos estaduais para fomento à C\&T. Essa ten- dência de fortalecimento de uma política de estado para a C\&T continuou a evoluir até o golpe de 2016, que depôs a presidente Dilma Rousseff e iniciou a desmontagem do estado democrático no Brasil.

O processo que se deu com C\&T não teve paralelos na Cultura. Embora discussões sobre uma política de cultura tenham sido fomentadas principalmente a partir do marco estabelecido pela Constituição de 1988, um Plano Nacional de Cultura só foi instituído em 2010, através da Lei 12.343.

Em um periódico como PragMATIZES é desnecessário repetir a importância da Memória e da Cultura para a construção da identidade de um povo. O que talvez seja novidade são os registros digitais e o papel atual da informação digital em Memória e da Cultura, processo que estamos vivendo atualmente. Em uma ecologia do digital, com uma capilaridade extraordinária, atingindo a todos, registros digitais em Memória e Cultura têm potenciais culturais, educacionais, para a cidadania novas e extraordinárias, que os acervos convencionais não possuem: um alcance, podendo ser consultados por qualquer um, de qualquer lugar e a qualquer tempo; e uma plasticidade, podendo ser copiados, e recombinados de várias maneiras. Inclusive do ponto de vista econômico estes registros vêm sendo considerados um insumo para as chamadas indústrias criativas, como pode ser constatado na página do projeto Europeana Creativel:

The project aims to support and promote the re-use of cultural resources that are made available via Europeana - a website that provides access to digital resources of Europe's museums, libraries, archives and audio-visual collections. Europeana Creative stimulated the re-use of this wealth of material by creative industries active in Design, History Education, Natural History Education, Social Media and Tourism. 
De fato, estes potenciais ainda são pouco conhecidos e explorados. Requerem maior conhecimento, conceitualização, planejamento e políticas públicas para que essas potencialidades sejam maximizadas. Levantar essa discussão é o objetivo do presente Dossiê.

Marco importante para as políticas públicas para acervos digitais em Memória e Cultura foi a proposta de Roberto Tadei, de 2010, "Políticas públicas para acervos digitais: propostas para o Ministério da Cultura e para o setor", produzido no contexto do Plano Nacional de Cultura (PNC), que prevê entre suas metas a digitalização de acervos e sua disponibilização na Web. A proposta de Tadei nunca foi publicada formalmente e, até onde se sabe, nunca saiu do papel. Aí estão colocados os pontos chaves para o sucesso e implementação de políticas públicas para acervos digitais.

A pergunta que não quer calar é porque não temos no país, implementada e consolidada, políticas públicas para acervos digitais? Embora tenham havido apoios a projetos de digitalização de acervos desde a primeira década de 2000 , esses apoios foram em nível de instituições e acervos isolados, com um viés de preservação digital desses acervos. Não houve ainda projetos interinstitucionais, que demandem articulação entre diferentes instituições, fóruns comuns. Talvez ai esteja o caminho para uma resposta. Nem o estado brasileiro enxerga a necessidade de uma política brasileira para acervos em Memória e Cultura (ao contrário do caso europeu, em que a Biblioteca Europeana é uma política do Parlamento Europeu), nem as instituições de Memória e Cultura Brasileiras se vêm (ou estão preparadas para) como participantes de projetos interinstitucionais de relativos a acervos digitais em Memória e Cultura. Talvez a importância desse Dossiê seja exatamente colocar esta questão.
Os trabalhos iniciais discutem questões mais teóricas. Os trabalhos de Carvalho Junior, Martins e Germani juntamente com o de Castro, discutem e conceitualizam os objetos digitais, questão essencial para qualquer agenciamento desses objetos.

A seguir, o trabalho de Bettencourt e Marcondes apresenta as questões técnicas e tecnológicas acerca do acesso integrado a acervos digitais, chamando a atenção para o fato de que as questões tecnológicas para se lograr o acesso integrado já estarem praticamente equacionadas.

Os trabalhos seguintes destacam vários casos e experiências brasileiras de digitalização e acesso a acervos digitais. Em primeiro lugar é relatada a experiência recente da Wikipedia brasileira e seu grupo GLAM (sigla para Galeries, Libraries, Archives, and Museums) em digitalizar e disponibilizar através dessa plataforma acervos brasileiros de diversos museus. Cabe aí destacar o papel cada vez mais importante que joga a Wikipédia na disponibilização de acervos digitais em Memória e Cultura (KLEIN; KYRIOS, 2013).

A seguir, o trabalho de Machado e Souza relata a experiência da rede Web de Museus do estado do Rio de Janeiro em disponibilizar, através de seu portal na Web, acervos digitalizados de diversos museus do estado, públicos e privados; a experiência é relevante pois mostra um trabalho em rede e cooperativo entre diferentes instituições, caso raro no Brasil.

O próximo trabalho, de Fujita e Troitiño, relata a experiência do CEDEM - Centro de Documentação e Memória da UNESP, na formulação de políticas para tratamento e digitalização de acervos relevantes para a história política social recente do Brasil, os dos movimentos político-sociais. 
O trabalho seguinte, de Garcia, mostra a experiência da Biblioteca Brasiliana da USP na digitalização do seu acervo, destacando as questões técnicas e compromissos que tiveram que ser assumidos na realidade de desenvolver um projeto de digitalização no nosso contexto. A seguir, o trabalho de Lima e Coelho destaca questões técnicas relativas à digitalização de acervos de um dos tipos mais disseminados e importantes de instituição de Memória e Cultura, os arquivos.

Finalmente o último trabalho, de Garcia-Moreno e Hernández-Perez, destaca de forma clara e ilustrativa as políticas europeias para acervos digitais em Memória e Cultura, centrados em torno do Projeto da Biblioteca Brasiliana. Temos muito que aprender com a experiência internacional, que não se restringe aos países do Primeiro Mundo; o México lançou recentemente a experiência da Mexicana - Repositório del Patrimonio Cultural de Mexico".

O conjunto de trabalhos deste Dossiê toca em várias questões importantes, mas também várias outras ficaram por discutir. Esperamos que este Dossiê possa disseminar experiências e incentivar as instituições brasileira de Memória e Cultura e os profissionais que nelas trabalham para seu protagonismo na formulação do uma política brasileira de acervos digitais. Que ele seja tão somente o início de uma discussão.

Carlos Henrique Marcondes, editor do dossiê

Niterói, janeiro de 2019

\section{Bibliografia}

BRASIL. Ministério da Cultura. Plano Nacional de Cultura. 2010. Disponível em: <http://pnc.cultura. gov.br/>. Acesso em: 31 jan. 2019.

BRASIL. Presidência da República. Plano Básico de Desenvolvimento Científico e Tecnológico, 1973/74. Brasília: IBGE, 1973.

BRASIL. Presidência da República. I/ Plano Básico de Desenvolvimento Científico e Tecnológico. Brasília: IBGE, [197]].

BRASIL. SEPLAN - CNPq. III PBDCT: Plano Básico de Desenvolvimento Científico e Tecnológico. Brasília, 1980.

KLEIN, M.; KYRIOS, A. VIAFbot and the integration of library data on Wikipedia. Code4Lib journal, v. 2, p. 85-107, 2013.

TADDEI, Roberto. Políticas públicas para acervos digitais: propostas para o Ministério da Cultura e para o setor. São Paulo: [s.n.], 2010. Disponível em: <https://pt.slideshare.net/Culturadigital/ politicas-publicas-para-acervos-digitais $>$. Acesso em: 13 dez. 2017.

I https://euroclio.eu/projects/partner-europeanacreative/.

II Ver https://mexicana.cultura.gob.mx/ 